\title{
Design da comunicação por imagens: da perspectivização à desestabilização do olhar ${ }^{1}$
}

\section{Neide Jallageas ${ }^{2}$}

1. Texto originalmente escrito em 2004, como capítulo de livro (inédito), durante o doutoramento da autora, sob orientação da profa. dra. Irene Machado. Mais tarde, o texto foi ampliado, incluindo estudos sobre a perspectiva inversa, do filósofo russo Pável Floriênski, para integrar capítulo da tese defendida em 2007. Para a presente publicação, o texto original foi reduzido para atender às normas da revista.

2. Pós-doutoranda no Programa de Pós-Graduação em Russo da Faculdade de Filosofia, Letras e Ciências Humanas da Universidade de São Paulo com estágio no Museu de Cinema Russo (Moscou) e com bolsa da Fundação de Amparo à Pesquisa do Estado de São Paulo. Doutora em comunicação e semiótica pela Pontifícia Universidade Católica de São Paulo e mestre em estética e comunicação do audiovisual pela Escola de Comunicações e Artes da USP. Docente (licenciada) no Centro Universitário Belas Artes de São Paulo. E-mail: neide.jallageas@gmail.com 


\section{Resumo}

O espaço e o tempo na arte são pensados a partir da transformação de hábitos perceptivos frente ao mundo visível, através das experimentações com imagens sequenciais e propostas radicais das Vanguardas, que, no início dos 1900, buscaram romper com os limites do espaço, através da inclusão do tempo em suas obras, na fronteira entre fotografia e cinema, explorando e intervindo em máquinas perspécticas.

\section{Palavras-chave}

Espaço-tempo, fotografia, cronofotografia, Fotodinamismo, cinema.

Abstract

Space and time in art are thought as from the processing of perceptive habits, front of the visible world, through experimentation with sequential images and radical proposals of the Vanguards, who, in the early 1900s, tried to break with the limits of space, by the inclusion of time in their work at the border between photography and cinema, exploring and intervening in perspective machines.

\section{Keywords}

Space-time, photography, cronophotography, Photodinamism, cinema. 
3. Segundo a "abordagem ecológica” de James Gibson (1986), é no ambiente que estão as disponibilidades à interação e as informações em deslocamento. $\mathrm{O}$ acesso às informações que daí podem ser extraídas se dá pelo processo direto entre o sujeito e o ambiente, por interação. Gibson utiliza o conceito de affordances ou disponibilidades como possibilidades de percepção que existem no ambiente.
Quando o ser humano ensaiava as suas primeiras formas de comunicação, gravando informações na superfície de uma caverna, teve início um ato que se repetiria até os dias de hoje: fazer uso de signos como forma de realizar suas ideias em um modelo de realidade. Nesse sentido, a arte é aqui compreendida - em qualquer período da história humana - em vínculo com o ambiente ${ }^{3}$ que propicia sua produção. $\mathrm{O}$ artista interage com as informações do mundo, do ambiente, e é no exercício de modelizar essa realidade percebida, elaborando sua obra, que opera uma linguagem para a compreensão da vida, assim como concebeu o semioticista russo Iúri Lótman (1922-1993), segundo o qual "uma comunicação artística cria um modelo artístico de um fenômeno concreto" (LÓTMAN, 1978, p. 50, grifo nosso).

Para traduzir o mundo visível em visão de mundo, o artista trabalha tanto com as limitações quanto com as potencialidades do tempo em que sua obra é produzida. Assim, pensemos nos desafios da caça e na precariedade técnica como disponibilidades (GIBSON, 1986) para o artista primitivo realizar os primeiros ensaios pictóricos rupestres. Da mesma maneira, a grandiosidade das esculturas gregas não se levantaria do mármore não fossem a abundância desse material nas regiões helênicas e a tecnologia alcançada para extraí-lo e dar-lhe forma. Em ambos os casos, o processo artístico se dá na relação do artista com o ambiente no qual se inserem não apenas a matéria da qual será constituída a obra, onde será gravada a informação, mas também a tecnologia necessária para gravá-la (o conhecimento já adquirido - ou em processo de aquisição - 
para a sua fatura), instrumentalizada por uma lâmina, um lápis, um pincel, uma câmera ou um computador. Nesse mesmo sentido, Vilém Flusser (1920-1991) concebe que: a arte "é sempre produção e preservação de informação. Um objeto de arte é informação armazenada em algum tipo de material — pedra, bronze, pintura - que a livra de ser esquecida [...]" (FLUSSER, 2002, p. 28).

Coube sempre aos artistas, nesse gesto, traduzir a vida, em toda a sua extensão e manifestação, e deixar essa tradução gravada como texto artístico. Ainda que, como argumenta Lótman, a arte "não represente uma parte da produção e a sua existência não seja condicionada pela exigência do homem de renovar incessantemente os meios de satisfazer as suas necessidades materiais (LÓTMAN, 1978, p. 25)", há 40 mil anos os artistas seguem tatuando a pele do tempo: o texto da cultura.

Eis um ponto do qual parto após essa breve exposição: o esforço de modelização realizado pela arte se faz em processo, no caldo da experiência artística humana, que sempre se renova em um movimento de ebulição da memória individual e coletiva, em programas de ação. Retomando Lótman:

\footnotetext{
Não é por acaso que a arte, ao longo do seu desenvolvimento, se liberta das mensagens envelhecidas, mas conserva na memória, com uma extraordinária constância, linguagens artísticas das épocas passadas. A história da arte transborda de "renascimentos" renascimentos das linguagens artísticas do passado recebidos como inovadores (LÓTMAN, 1978, p. 47).
}

Assim, tomando a arte como linguagem em constante movimento, ação e renovação, proponho pensar o design da comunicação por imagens, através da trajetória da "perspectivização da cultura", desde as suas primeiras modelizações inscritas em determinados aparelhos semióticos tradutores de signos até o período maior de ruptura ou de recodificação, percurso esse que se dará na conexão da linguagem da arte com a linguagem da ciência, alcançando o momento em que as bases culturais que suportaram essa trajetória passam a ser drasticamente abaladas por movimentos transgressores de sua tradicional codificação, no início do século XX. 


\section{A perspectivização cultural do olhar}

Sob o ângulo da constituição histórica dos sistemas da ciência e da arte, é a partir do Renascimento que o design da comunicação por imagens passa a ser mediado por máquinas perspécticas. A expressão “máquinas perspécticas” é minha opção de tradução do conceito de Martin Kemp (s. d.), "perspective machines", em seu estudo The science of art: optical themes in western art from Brunelleschi to Seurat (1990). Nessa obra, Kemp, ao introduzir o capítulo no qual detalhará a invenção de máquinas ou aparelhos, contextualiza o momento em que a perspectiva passa a ser desenhada com o auxílio de máquinas, de tal forma que nos é impossível não estabelecer uma relação da construção dessa visualidade renascentista com o seu tempo:

\footnotetext{
Eu não penso que seja mera coincidência que também tenha sido esse o período em que as tecnologias de aparelhos científicos e utilitários passaram a ocupar um lugar central nos esforços dos europeus para o progresso intelectual e material. Certamente, a noção geral do progresso nessa etapa do pensamento ocidental é compartilhada profundamente pela ciência, pela tecnologia e pela arte naturalista (KEMP, 1990, p. 167).
}

Da mesma forma, os pesquisadores franceses René Taton (19152004) e Albert Flocon (1909-1994) relacionam a cultura visual do Renascimento com a aceleração dos processos de comunicação possibilitados pelo surgimento da imprensa:

\footnotetext{
Multiplicadas pela imprensa, as imagens criadas pelos artistas do século XVI revolucionam os antigos hábitos visuais. A partir de então, o mundo será visto de outra maneira. Regida por uma teoria matemática, a visão proposta iria fixar para os séculos vindouros a natureza dos espetáculos do Theatrum Mundi, Weltanschavung, visão do mundo - no sentido mais estrito do termo - , e sua qualidade mais apreciada estava, precisamente, na exatidão de sua "imitação da Natureza" (TATON; FLOCON, 1967, p. 56).
} 
Trata-se aqui do esforço empreendido pelos artistas do Renascimento para levar à superfície plana a tradução estática de um mundo que seus olhos percebiam como sendo de fenômenos contínuos e móveis (TATON; FLOCON, 1967, p. 13). Inicia-se a perspectivização da cultura visual, ou seja, há uma modificação radical na forma pela qual a informação visual é codificada. $\mathrm{O}$ conjunto de códigos perspécticos passa a ser sistematizado com a invenção da câmera escura e de outros aparelhos organizadores de sinais luminosos. Pela primeira vez, os artistas começam a fazer uso de uma programação, ou seja, da capacidade de produzir signos através de aparelhos.

Na Figura 1, observa-se o modo pelo qual o pintor se coloca diante do aparelho, através do qual pode "ver" e reproduzir, desenhando, o seu objeto. Para que a operação seja eficaz, ambos, o pintor e o retratado, devem reduzir seus movimentos ao mínimo necessário. O aparelho assim o exige, pois a pessoa que posa para o artista não pode se mover, ao mesmo tempo que o artista não deve mudar de posição, pois o seu olho (note-se que a visão é monocular) deve permanecer em um único ponto do espaço (o do ponto de vista único, ditado pelo aparelho) diante da pessoa que posa, de tal forma que o retrato seja a cópia mais fiel possível do "real”. Sabemos que nessa atmosfera envolta em silêncio a velocidade ainda não existe.

Figura 1: artista utilizando vidro com posicionador de olho para fazer um retrato; entalhe de Albrecht Dürer, Nuremberg, 1525

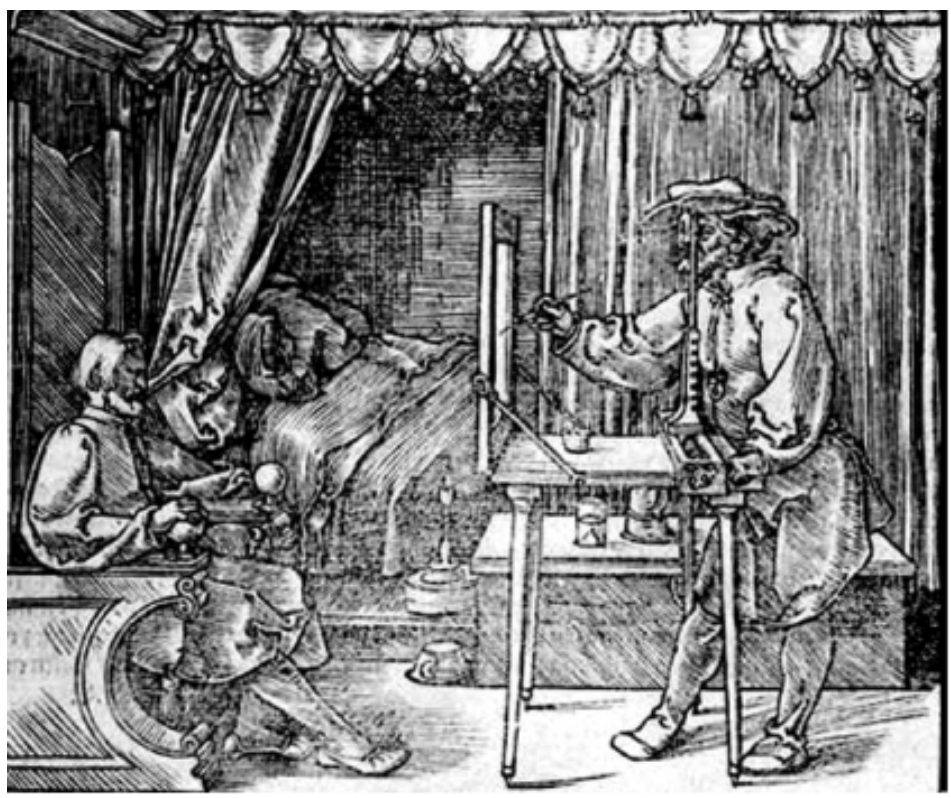


Chegará um momento em que esses corpos se deslocarão de seus pontos fixos, estacionários. Os motores substituirão as carruagens, as chamas das velas cederão à eletricidade. A luz gravará as imagens em sais de prata, e a agitação colocará em frenesi todas as coisas instauradas sob o signo da modernidade. Máquinas mecânicas imprimirão velocidade e maior precisão à reprodução das imagens em um tempo alterado, deslocando o espaço de contemplação em um mundo de ações fragmentárias, agitando no ar inapreensíveis marcas de sua aceleração e impaciência.

Mas voltemos nossa atenção à arte do Renascimento, pois é justamente nesse período que os artistas da imagem começam a olhar "através de". A utilização de aparelhos intermediários não apenas fará toda a diferença no processo, mas provocará alterações na codificação realizada na fatura da obra. Como consequência, tais aparelhos passam a determinar toda forma de perceber o mundo através de imagens.

O olhar assume-se matemático. É a matemática que passa a organizar as formas que serão traduzidas em linguagem. E é através desse aparato matemático, perspéctico, que será modelizado o sistema das artes visuais. É dada a largada para a perspectivização da cultura, cuja radicalização é alcançada com a fotografia propriamente dita, a partir da primeira metade do século XIX.

Curioso, no entanto, é observar que, se os princípios da linguagem fotográfica aprisionarão de vez a perspectiva em sais de prata, serão esses mesmos princípios que apontarão o caminho de saída através, mais uma vez, da relação do fazer artístico com o ambiente.

Desse modo, entre o século XIX e o XX, o ar torna-se mais poluído e denso: é a chegada dos motores, com seus óleos, vapores, combustão, e da velocidade. Perder-se-á o prazer ou dor da lentidão, surgirá toda a sorte de experiências artísticas que tentarão dar conta dessa nova configuração do modus vivendi no planeta: os artistas irão sorver até a última gota que puderem desse fluido abrasante e invisível denominado eletricidade, para depois vomitar a tradução, em múltiplas visões, relacionando o ser humano com o legado das máquinas mecânicas e elétricas: o movimento, o dinamismo, a impetuosidade. 
4. Momento futurista é o título de um estudo de Marjorie Perloff.

A autora conta que retirou esse

título de Renato Poggiolli (The theory of the avant-garde) e cita o trecho no qual o autor sugere: "o momento futurista pertence a todas as vanguardas e não só àquela que teve esse nome $[\ldots]$ o movimento assim denominado foi apenas um sintoma significativo de um estado mental mais amplo e profundo"

(PERLOFF, 1993, p. 19).
Entre a Renascença e as Vanguardas Históricas (início dos anos 1900), quatro séculos se passam, até que as imagens contaminadas pela perspectiva sejam desafiadas pela aceleração e estabeleçam relações com outros sentidos. E eis que chegamos ao recorte mínimo do presente ensaio: o fotográfico, através do qual encaminharei agora algumas possibilidades de percurso para o estudo do design da comunicação por imagens em um momento explosivo da cultura.

O fotográfico aqui discutido ultrapassa a função de adjetivo; realiza-se em linguagem, integrando um sistema da cultura codificado pela perspectiva. Abarca inclusive o conceito de fotografia, mas não se restringe a ela. É substantivo em cuja totalidade abrange tanto a perspectiva artificialis como a perspectiva naturalis. Para dotar de clareza essa distinção, recorro a Taton e Flocon:

\footnotetext{
A palavra prospectiva ou perspectiva designava, no latim da Idade Média, a ciência óptica que os gregos chamavam de [...] optikê, ciência que trata dos fenômenos luminosos. A perspectiva geométrica, elaborada pelos artistas, chamar-se-á então perspectiva artificialis, enquanto a ótica [sic.] receberá o nome de perspectiva communis ou naturalis (TATON; FLOCON, 1967, p. 47).
}

O modelo perspéctico geométrico é sabidamente um artifício que codifica o fotográfico, sistema da cultura que se constituiu a partir do uso de máquinas perspécticas, no Renascimento. A cultura visual, desde então, foi se formando por meio da representação de um modelo geométrico. Dessa maneira, o olhar humano conformou-se ao fotográfico muito tempo antes do advento da própria fotografia. Ter em mente que os pontos que são intersectados para formar a imagem efetivam a sua codificação, com o objetivo de construir uma imagem "perfeita" do real, é imprescindível para a compreensão da recodificação posterior dessas imagens, aqui entendidas como textos da cultura.

Até o "momento futurista", no princípio do século XX, os gêneros não eram colocados em dúvida. Desenho era desenho, gravura era gravura, pintura era pintura e, assim, o mundo das imagens estava organizado segundo "as medidas que configuram 
“a proporção divina”' (TATON; FLOCON, 1967, p. 46). Ou seja, as técnicas definiam o gênero, mas toda cultura da visualidade instituída pela classe erudita desde o Quattrocento até a segunda metade do século XIX obedecia às regras da perspectiva geométrica, ou artificialis, submissa aos cânones da divina proporção, cuja frase lapidar, de Leon Batista Alberti, sentenciava que "um quadro é uma janela através da qual observamos uma seção do mundo visível” (apud TATON; FLOCON, 1967, p. 52). A moldura quadrada ou retangular dessa seção do mundo visível constituía-se em um limite material dentro do qual se desenhavam informações visuais codificadas pela perspectiva advinda da geometria que traduzia o mundo visível em conceito de mundo.

Formulada de uma maneira ainda bastante geral na Antiguidade clássica, a geometria euclidiana estrutura-se no Renascimento. Os cálculos numéricos necessários para alcançar a "Divina proportione", que eram os codificadores da visualidade ("cosa mentale", segundo Da Vinci), passam a ser finalmente traduzidos espacialmente em desenhos através de máquinas perspécticas criadas na Renascença, cujo conhecimento nos chega através de vasta documentação deixada pelos artistas pesquisadores ou artistas geômetras, como Filippo Brunelleschi (1377-1446), Leonardo da Vinci (1452-1519) e Albrecht Dürer (1471-1528), entre os primeiros a ocupar-se desses estudos e produção de trabalhos artísticos através de máquinas, e outros cientistas, como Hieronymus Rodler (1539-?) e Daniel Barbaro (1514-1570). Assim, desde o Quattrocento, as máquinas “portais" de Dürer, os perspectógrafos de Cigoli (1559-1613), passando pela câmera obscura, a câmera lúcida, até a chegada da câmera fotográfica, nos anos 1900, as máquinas perspécticas vêm desenhando, com maior ou menor interferência humana, a comunicação por imagens.

\section{Traduzir a tradição ou subverter o fotográfico}

Entre a Renascença e as Vanguardas Históricas, ecoam em nossos ouvidos duas frases emblemáticas. A primeira, proferida por Alberti, enunciada acima ("um quadro é uma janela através da qual observamos uma seção do mundo visível”), refletia um olhar 
5. As janelas de minha poesia são grandes aberturas sobre os bulevares. atravessado pela codificação da perspectiva artificialis. A segunda voz, emitida muitos séculos depois, nasce da sensibilidade do poeta Blaise Cendrars (1897-1961), que, em 1913, lança seus poemas curiosamente chamados "elásticos", iniciando com o seguinte verso, que mantém com Alberti um diálogo irônico: "Les fenêtres de ma poésie sont grand'ouvertes sur les boulevards"5. Essas fenêtres parecem querer romper os limites entre os olhos que veem o mundo e o mundo que é visto: aberto, não mais seccionado. O poeta busca a elaboração de um texto artístico que se aproxima do mundo, que cumpre seu destino de interagente, de dispositivo dialógico, assinalando o movimento que os artistas de seu tempo passam a realizar junto ao que pulsa nos cafés, nas pontes, nas galerias, nas portas das lojas e fábricas, em cada esquina do espaço onde habitam.

$\mathrm{Na}$ virada do século XIX para o XX, o tempo atomiza-se. Os artistas do momento futurista percebem a fugacidade da matéria em trânsito. A percepção da paisagem incorporando-se ao humano e muito mais, a paisagem vista, em velocidade - vira tempo, vira signo... (PIGNATARI, 1985, p. 90).

A partir desse momento, fica instalada a proposta de conexão da arte com a vida. Entendamos aqui vida no contexto estudado: vida não apenas considerada como bios, mas vida atuante em seu contexto, articulando-se, pulsando em seu tempo, um sistema conectado a outros, em crescentes multiplicidade e complexidade. A paisagem transtornada por seguidas metamorfoses oferecia não apenas a percepção cada vez mais caótica e fragmentária, dos bondes, trens, apitos de fábricas, máquinas e toda a sorte de ruídos que preenchiam as metrópoles. A conformação desse meio urbano agregou um ritmo de vida cuja velocidade frenética fora desconhecida até então, implicando, conforme aponta Jacques Aumont, a constituição "de um novo espaço-tempo, fundado na destruição física do espaço-tempo tradicional, mas também na substituição da moral antiga ligada à natureza por valores novos, o desejo de aceleração, a perda das raízes" (AUMONT, 2004, p. 53).

A arte traduziria avidamente essa visão em um modelo de mundo em transformação e, para isso, também foi necessário o 
exercício de novas apropriações ambientais. Cito o teórico russo Mikhail Bakhtin (1895-1975) e sua precoce visão ecológica que relacionou insistentemente a arte à vida, na qual o "autor" se constitui no processo colaborativo, em diálogo constante com o “outro”, em que o texto artístico não é uma representação mimética do ambiente, mas resultado de uma ou mais interações dinâmicas em um contínuo processo de vir a ser (BAKHTIN, 1997). Novos meios se agregavam às máquinas perspécticas. Esses meios estavam disponíveis já no século XIX. Dos instrumentos ópticos, podemos citar, a título de exemplo, o telescópio gráfico, o espelho gráfico e a câmera periscópica, o megascópio solar e tantos outros instrumentos. Todos eles eclipsados pela invenção da fotografia (SCHARF, 1994, p. 26) e, finalmente, pela invenção da câmera fotográfica propriamente dita.

E, mais além da câmera fotográfica, é fundamental convocar para esse inestancável fluxo de reprodutibilidade técnica os equipamentos desenvolvidos por cientistas que se ocupavam do estudo dos movimentos dos seres vivos e colocam em marcha toda a complexa estrutura técnica do cinema. Refirome principalmente às imagens sequenciais do fotógrafo inglês Eadweard Muybridge (1830-1904) e à cronofotografia do fisiólogo francês Étienne-Jules Marey (1830-1904).

Muybridge realizava suas produções nos Estados Unidos, em Palo Alto, a partir de 1872. Lá, montou uma estrutura especial para dispor uma série de câmeras fotográficas ao longo de um caminho que seria percorrido por cavalos. Sensores disparavam cada câmera, conforme o corpo em movimento se aproximava. Durante anos o fotógrafo, com o auxílio da engenharia óptica, conseguiu aperfeiçoar suas câmeras, que passaram a alcançar tempos mais curtos de exposição.

Já a pesquisa de Marey, na França, desenvolveu-se através da construção de diversos aparelhos. Entre eles, destaca-se o fuzil fotográfico, que possibilitava gravar uma sequência de imagens de um mesmo corpo em movimento em uma mesma chapa. Marey dedicaria toda a sua vida ao estudo do kinema (movimento). Seu conceito de cronofotografia foi responsável por uma pesquisa 
consistente sobre corpos em movimento, de cunho científico, que influenciou o trabalho de muitos artistas, tais como Marcel Duchamp (1889-1968) e Francis Bacon (1909-1992). Ao lado de outros cientistas, Marey realizou, inclusive, curtos filmes (imagens em movimento, cinema) até hoje preservados em coleções públicas, como a Cinemathèque Française (MANNONI, 2003, p. 319-358).

Integrando a densidade crescente de novas tecnologias e experimentações no século XIX, frente às ameaças da fotografia aos meios tradicionais de reprodução, os artistas inquietam-se, e a era dos "ismos" inicia seu curso de provocações. Por meio de manifestos seguidos, cada vez mais audaciosos, das mais diversas áreas (pintura, escultura, teatro, música etc.), a Vanguarda Futurista, movimento inaugurado na Itália, com um explosivo manifesto em 1909, pelo poeta Filippo Tommaso Marinetti (1876-1944), se espalhou por toda a Europa, contaminando e impulsionando outros movimentos.

A Vanguarda Futurista combateu explícita e incansavelmente o passado e a tradição. Com os pés fincados no mundo físico do presente e a cabeça na velocidade, os seus mentores artísticointelectuais, que acima de tudo cultuavam a máquina, ironicamente, rejeitaram o Fotodinamismo Futurista, depois de tê-lo acolhido, tão logo os resultados mostraram o potencial como arte.

Três linguagens podem ser convocadas para compor as experiências do Fotodinamismo Futurista: a fotografia, o cinema e a performance. O manifesto dos fotodinamistas, publicado pelo jovem italiano Anton Giulio Bragaglia, deixa claro que os autores das experiências fotodinâmicas (Anton e seu irmão Arturo) objetivavam refutar qualquer possível relação que pudesse ser feita entre a fotodinâmica, a fotografia, a cinematografia e a cronofotografia. Admitiam apenas que o único fato comum a elas seria o técnico, ou seja, a câmera fotográfica, da qual todas essas manifestações derivam.

Ora, em seus primórdios, a técnica fotográfica exigia longos tempos de exposição, motivo pelo qual os fotógrafos retratistas faziam uso de suportes para apoiar pescoço e cabeça de seus retratados, (Figura 2), pois, com o longo tempo de exposição, o corpo tende a mudar de postura e, caso isso ocorra, no momento 
em que a fotografia está sendo impressa na película, o mais leve movimento será impresso com a aparência de um "borrão", fazendo que a imagem fotográfica deixe de ser uma "cópia fiel da realidade". Notemos aqui o mesmo procedimento de rigidez de corpos já analisado no uso das máquinas perspécticas durante o Renascimento.

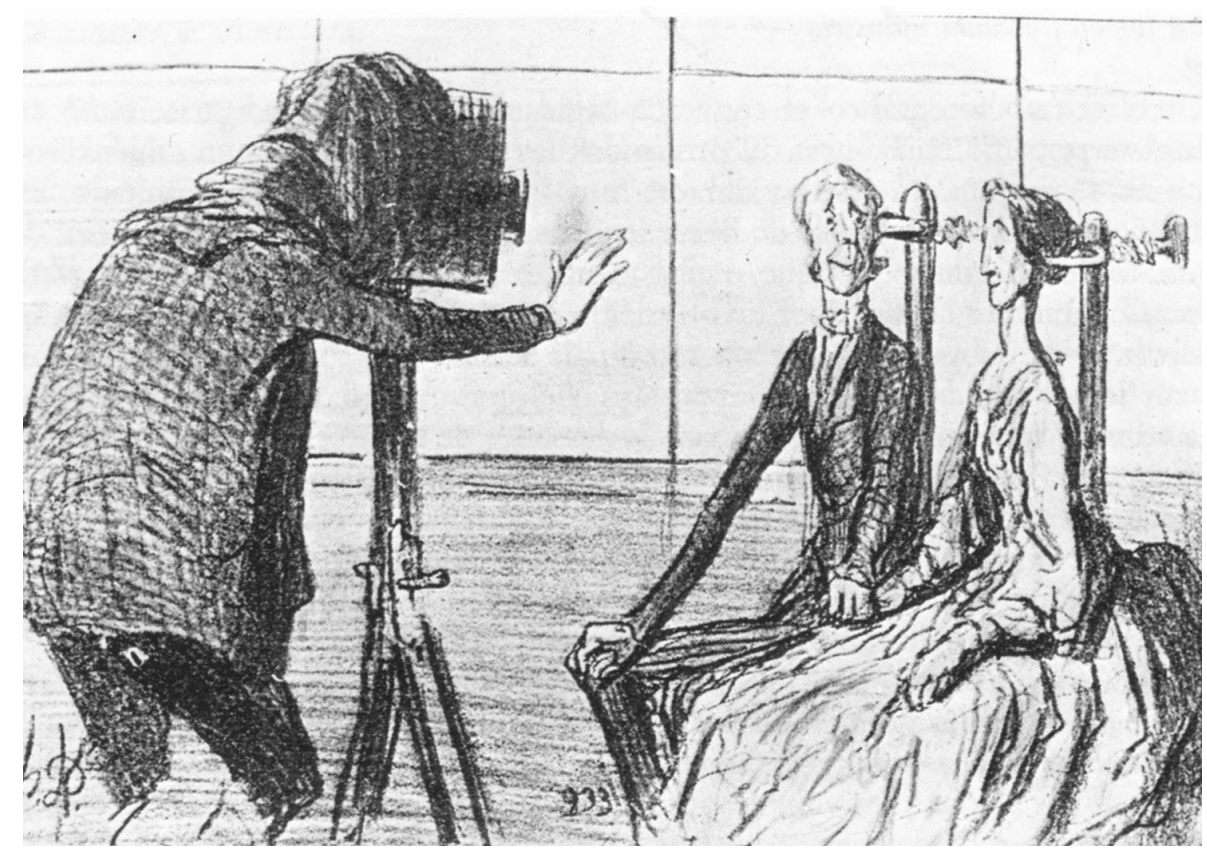

Figura 2: Daumier, Photographie. Nouveau procédé, 1856 (litografia)
À medida que a tecnologia da fotografia se desenvolvia, ela foi permitindo tempos mais curtos de exposição, porém mais pesquisas seriam necessárias para alcançar resultados considerados satisfatórios. Ainda em 1867, as fotos que incluíam pessoas andando pelas ruas, por exemplo, apresentavam borrões como registro dos corpos em movimento, durante a tomada da imagem. Semelhante resultado causava estranheza ao público, cujos olhos, acostumados aos padrões do design da comunicação por imagens renascentista, não conseguiam assimilar essas "imperfeições".

O aperfeiçoamento técnico do equipamento fotográfico objetivava a produção de imagens fotográficas "estáveis", assim como os retratos eram estáticos na pintura, baseados em modelos imóveis. Apenas desse modo a fotografia poderia ser considerada "artística", “cópia fiel da realidade” tal e qual a pintura, desde os 1500. 
Figura 3: Marey: cronofotografia de um esgrimista. 1880-90. Archives de Cinemathèque Française, Paris.
Os sistemas de signos se correlacionam, e suas esferas, conforme Lótman, se interseccionam ou simplesmente fazem fronteira entre si (MACHADO, 2003, p. 99). Assim, buscar que a fotografia se equipare à pintura, retrocedendo, equivale ao que a semiótica russa (semiótica da cultura) conceitua como tradução da tradição. Do encontro entre as duas culturas diferentes (pintura e fotografia, embora ambas tenham sido codificadas pelo fotográfico), buscase uma tradução da tradição perspéctica: que a fotografia seja modelizada pela pintura.

Agora, observemos uma cronofotografia de Marey (Figura 3) e uma fotodinâmica de Bragaglia (Figura 4). Se o que os fotodinamistas almejavam obter através da câmera fotográfica era a trajetória do gesto e daí o dinamismo da fotografia (a fotodinâmica), aparentemente, a cronofotografia de Marey também cumpria esse objetivo.

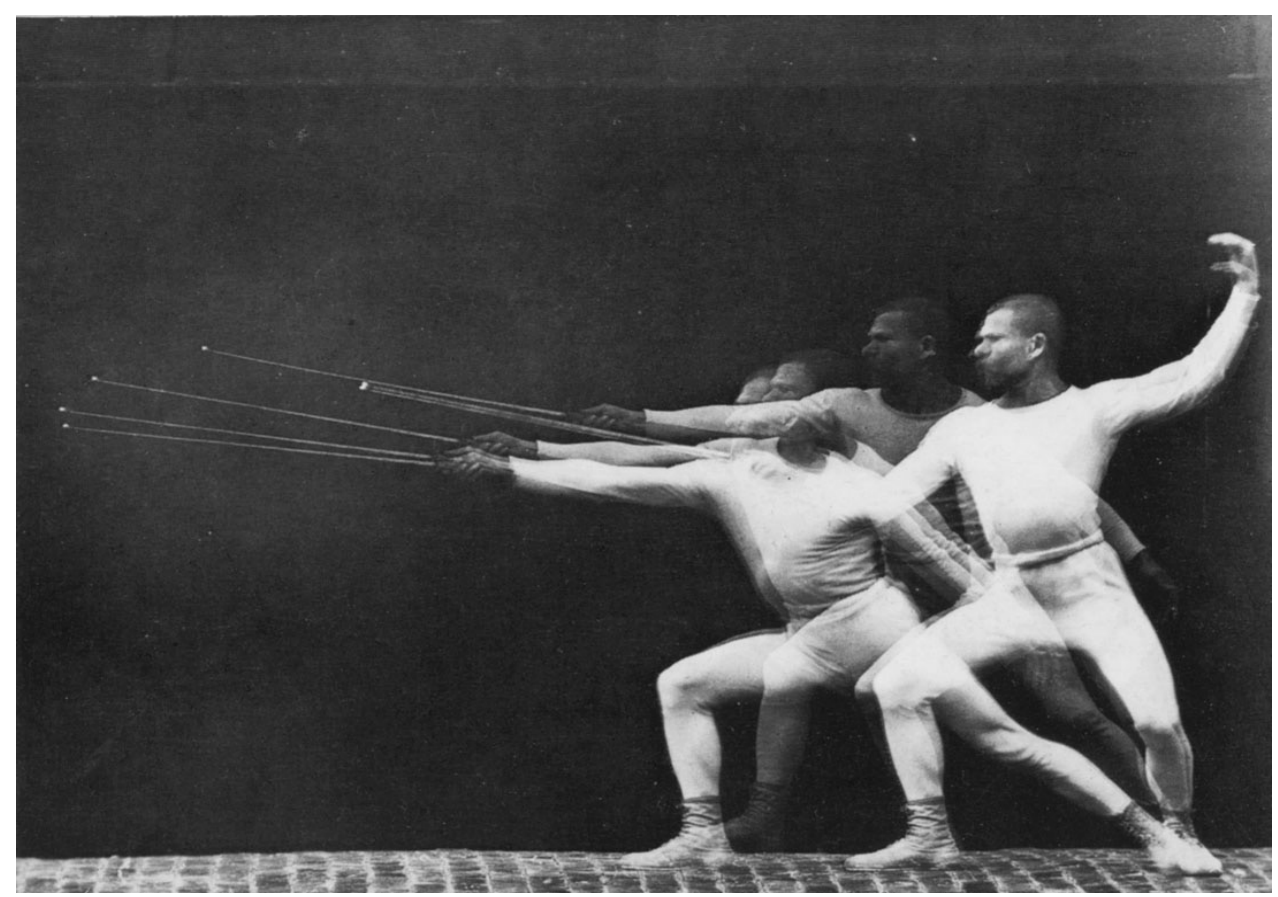




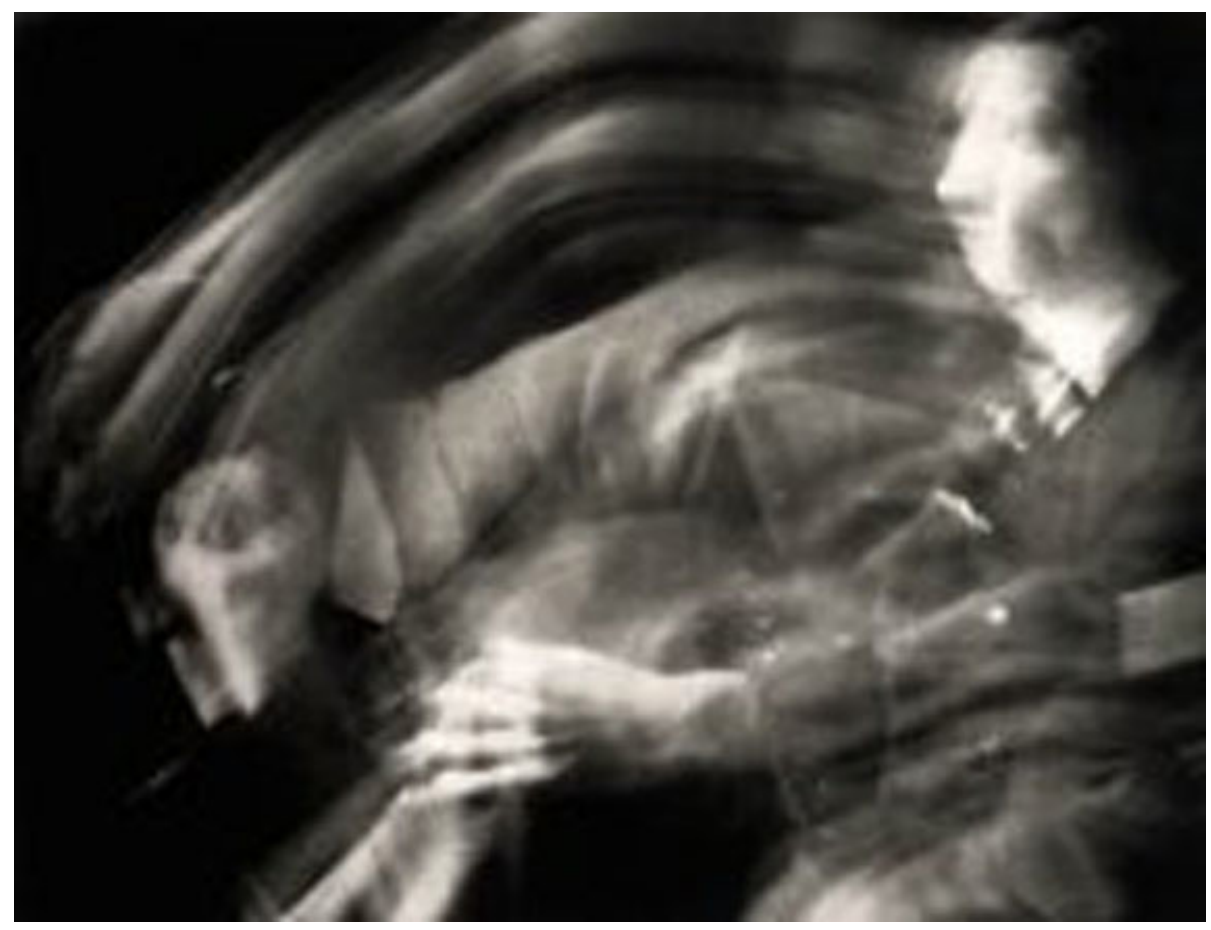

Figura 4: Anton Giulio Bragaglia, Cambiando de postura, fotodinâmica, 1911, 12,8 x 17,9 cm, Gilman Paper Company, Nova Iorque
Marey buscava o percurso do movimento: portanto, a forma pela qual esse trânsito poderia ser inscrito em seu dinamismo, no espaço. No entanto, as duas experimentações partiam de campos de observação e dispositivos distintos: Marey, da ciência, e Bragaglia, da arte; Marey, com equipamentos especialmente fabricados para registrar o que lhe interessava para o estudo da fisiologia; e Bragaglia intervindo no aparelho, incorporando os potenciais ruídos das informações visuais - os borrões - , radicalizando-os ao máximo, utilizando longos tempos de exposição. Os dois sistemas dialogam, se contaminam, e é mesmo curioso que, quando publica seus estudos científicos, Marey os nomeie de Études: phisiologie artistique, demonstrando que seu trabalho científico, de alguma maneira, adentrava as fronteiras da arte. E, quanto a Bragaglia, embora tenha utilizado a maior parte do manifesto para argumentar sobre as diferenças entre a representação mecânica do movimento pela cronofotografia e a fotografia transcendental do movimento (a fotodinâmica), subverte o determinismo mecânico da câmera, pois, resvalando na fronteira da ciência, não o faria se não tivesse 
6. Todos pintores futuristas, sendo Russolo um dos precursores da música concreta.

7. Parte dessas questões foram inicialmente levantadas na pesquisa que resultou em minha dissertação de mestrado (JALLAGEAS, 2002),

retomadas em comunicações apresentadas em congressos e/ou publicadas em capítulos de livro (LYRA; GARCIA, 2001, 2002 e GARCIA; NOJOSA, 2003).Tais inquietações estimularam ainda a produção de séries de trabalhos artísticos em fotografia e vídeo (www. neidejallageas.com.br). conhecimento dos procedimentos através dos quais o equipamento fotográfico codifica as imagens que produz.

A busca de Marey é distinta da de Bragaglia, muito embora, à primeira vista, possamos pensar que se trata de um mesmo gênero de fotografia. A cronofotografia, acima de tudo, é realizada objetivando a precisão, o método que descarta falhas, busca explorar novos caminhos para a ciência. E, para a comunicação por imagens, essas pesquisas científicas trariam um novo conjunto de códigos visuais, um sistema que se lançou em ponte entre os velhos modelos artísticos e novos fenômenos concretos. Como assinala Giovanni Lista: "A poética do dinamismo conduzia naturalmente Umberto Boccioni (1882-1916), Carlo Carrà (1881-1966), Luigi Russolo (1883-1947), Giacomo Balla (1871-1958), Gino Severini (1883-1966) ${ }^{6}$ a considerar a fotografia científica como uma possível matriz, instrumento formal da arte futurista” (LISTA, 2001, p. 133).

Os pintores futuristas já haviam lançado dois manifestos, antes que Bragaglia se posicionasse. Para eles, é a "sensação dinâmica" que ansiavam eternizar (BOCCIONI, 1980, p. 41), a atmosfera, a sensorialidade, em um espaço que se fragmenta. Ambicionavam o dinamismo nas imagens para modelizar em pintura os fenômenos concretos no mundo agitado do telégrafo, das ferrovias, movimentos rápidos e multiplicados, construções verticais, trilhos, brilhos e muita fumaça.

E, quando as fotodinâmicas surgem nesse território eletrizado, incorporam o potencial tecnológico para romper com a estaticidade, com a rigidez da pose e passam a ser fruto de performances ${ }^{7}$. As informações são recodificadas e instauram um novo gênero em trânsito dentro da fotografia, como subversão do fotográfico, cujo princípio calcado no modelo estritamente geométrico exigia corpos estáticos, jamais performáticos.

\section{Fotodinamismo Futurista: um gênero em trânsito}

Examinaremos agora como o Fotodinamismo Futurista se efetivou em linguagem, meio ao qual estava disponibilizado pelos sistemas da cultura, considerando-se não apenas os conhecimentos 
8. Dentro do Futurismo italiano existiam regras para que um texto fosse considerado (ou não) um manifesto. anteriores à sua concepção mas também os conhecimentos concomitantes ao nascimento da fotodinâmica, como é o caso do cinema e da performance.

Anton Giulio Bragaglia torna público, em 1911, em tom defensivo, o que ficaria sendo conhecido como Manifesto do Fotodinamismo Futurista. Conforme afirma Giovanni Lista:

\begin{abstract}
A partir de 1911, no seio do futurismo surge a hipótese estética e criativa de uma "fotografia futurista", inaugurada por Anton Giulio Bragaglia, que lançou a "fotodinâmica". Depois da primeira experiência, tecnicamente conduzida junto ao seu irmão Arturo, Anton Giulio Bragaglia publicou um livro teórico sobre o Fotodinamismo Futurista, com um apêndice iconográfico que, entre 1912 e 1913, conheceu três edições sucessivas sem que qualquer modificação tenha sido efetivamente realizada (LISTA, 1979, p. 61).
\end{abstract}

O texto foi acolhido por Marinetti como um manifesto legitimamente futurista $^{8}$. Importante ressaltar que os experimentos de Bragaglia datam, historicamente, do ano de 1909, sendo anteriores à primeira publicação de sua teoria.

Foi renegando a validade da instantaneidade (eu prefiro a palavra estaticidade), qualidade tão cara ainda hoje aos mais conhecidos e renomados pesquisadores da fotografia e mesmo aos fotógrafos (veja-se por exemplo o ainda cultuado conceito de “momento decisivo", elaborado por Henri Cartier-Bresson), que Bragaglia passou a investigar a possibilidade de processar novas informações fotográficas, através da percepção de espaços não visíveis. Estes não são espaços "do além”, apesar de que, ao mesmo tempo que os artistas faziam seus experimentos fotodinâmicos, grupos voltados ao comércio do entretenimento, da adivinhação, realizavam as bastante populares fotografias de mortos, em supostas sessões mediúnicas, que apareciam como espectros, ectoplasmas, fantasmas etc.

Os espaços não visíveis dos fotodinamistas distinguem-se ainda do conceito de inconsciente óptico de Walter Benjamin (1986, p. 
94), voltado à compreensão de estados psicológicos de dada situação que o consciente humano não consegue alcançar. As imagens fotodinâmicas resultaram das possibilidades técnicas em devassar espaços inexplorados, para modelizar a vida caótica e movimentada do mundo, em seu tempo, captar-lhe a "atmosfera". Essa ideia, inclusive, sistematiza os manifestos futuristas, sem exceção. Em outras palavras: o que orienta as pesquisas dos fotodinamistas é a possibilidade de capturar, com o uso de uma câmera fotográfica, imagens formadas em intervalos de tempo que a mente não consegue registrar, mas a câmera sim. Trata-se da ação de inscrever o tempo em um único fotograma. Tal "inscrição do tempo" pode também ser compreendida como a "duração" do gesto encenado ou performatizado - em determinado espaço-tempo.

Ainda que as artes do corpo mal se anunciassem nos interesses desses artistas, na primeira fase do movimento, essas experiências deixam em aberto a relação entre o gesto de fotografar e o gesto de ser fotografado (JALLAGEAS, 2004), o que irá se contrapor à atitude dos pintores e modelos renascentistas. Rompe-se radicalmente com a rigidez do corpo, tanto do fotógrafo quanto do modelo. Por outro lado, as imagens assim obtidas questionam se as teorias existentes sobre a pose estariam de fato abarcando as complexidades da inscrição do tempo em uma fotografia dita "estática", o que está intimamente relacionado com o corpo que posa. E é aí que a hipótese da performance como subversão da pose pode ser aprofundada, o que deixaremos para um outro momento.

Lista observará também esse horror dos futuristas ao estático e sua obsessiva busca para trazer à arte a percepção dinâmica, o que resultará no que o estudioso italiano denomina de fotoperformance (LISTA, 2001, p. 135). Desse modo, a instantaneidade na captura da imagem, propriedade da fotografia que demandara séculos de pesquisa nos campos da física, da química e da própria arte, é drasticamente refutada por Bragaglia, que a identifica - enquanto propriedade - tanto na fotografia propriamente dita como na cronofotografia e, consequentemente, no cinema, pois, segundo o seu entendimento, um e outro, fazendo uso da instantaneidade, geram imagens que "quebram o movimento". Já 
em relação ao cinema, o fotodinamista argumenta que ele não salienta o traço do movimento, mas o reparte, sem lei alguma, num arbítrio mecânico, desintegrando-o e fragmentando-o, sem preocupações estéticas de nenhuma espécie em relação ao ritmo, recortando a realidade "friamente".

Em seu manifesto, Bragaglia busca demonstrar que a imagem, obtida através seja da fotografia, seja da cronofotografia, seja do cinema, não dá conta do que seria o objetivo fundamental do Fotodinamismo: tornar visível a trajetória contínua do movimento. Um de seus argumentos é a distinção que existiria entre anatomia e anatomia do gesto. Esta se constitui no que o fotodinamista denomina "representação movimentista", que se distingue da anatomia, cujo vínculo é com a representação estática (corpos imóveis, mortos, sem vida) (BRAGAGLIA, 1980, p. 64-67). Aponta ainda a inequívoca conexão de seu pensamento com a então contemporânea filosofia bergsoniana para ultrapassar o humano:

\footnotetext{
Na mobilidade vivente das coisas, o intelecto preocupase em assinalar umas estações reais, virtuais; ou seja, marca algumas partidas e algumas chegadas. É tudo aquilo que importa ao pensamento do homem enquanto simplesmente humano. Captar aquilo que sucede no intervalo é mais do que humano (BRAGAGLIA, 1980, p. 69-70, grifo nosso).
}

Outra nota dominante no conjunto de manifestos do momento futurista é a percepção de que a obra é completada pelo público. A preocupação com a participação do público remete à necessidade inaugural desses artistas em articular significados através do olhar do outro, em um processo dialógico que perdurará até os dias de hoje. Aliás, entre 1920 e 1930, Mikhail Bakhtin, décadas antes de Umberto Eco lançar a Obra aberta, será o grande teórico a investigar e a desenvolver as implicações epistemológicas da afirmação inicial de que " o acontecimento estético, para realizarse, necessita de dois participantes, pressupõe duas consciências que não coincidem" (BAKHTIN, 1997, p. 42). O desenvolvimento dessa teoria conecta-se diretamente com as propostas artísticas 
9. Exotopia (exotopie, em francês)

é tradução do russo, realizada pelo filósofo búlgaro radicado na França Tzvetan Todorov, de um neologismo criado por Bakhtin, em russo: vnenakhodimost, cuja grafia é вненаходи-мость.

Há divergências nas traduções

brasileiras. Eu mantenho exotopia por ter acepção mais próxima da dimensão conceitual

de Bakhtin, conforme minha interpretação: exo, corresponde ao adv. prepositivo grego éksó, "fora, de fora, por fora, afora", e topo, pospositivo, do grego tópos, ou "lugar" (Cf. HOUAISS); tal interpretação alinha-se com a interpretação (e tradução) realizada por Todorov que caminha no sentido da alteridade e criação artística. Transcrevemos a seguir

as suas palavras, traduzidas do francês: "A esse segundo aspecto da atividade criadora Bakhtin reserva uma denominação que é, em russo, um neologismo: 'vnenakhodimost', literalmente 'o fato de encontrar-se fora', e que traduzirei, literalmente novamente, mas através de uma raiz grega, por exotopia" (TODOROV, 1981, p. 153). vanguardistas que deslocam o papel do receptor passivo para o sujeito ativo, que responde à provocação da obra.

O empenho dos fotodinamistas em distinguir a fotografia, a cronofotografia e o cinema da força de subversão da fotodinâmica configura-se estratégico para marcar o nascimento de uma nova linguagem, cujos códigos, embora produzidos por uma máquina perspéctica de última geração (até aquele momento), calcada no fotográfico, sofrem uma intervenção, justamente no momento em que são produzidos, por conta da luz que, dinâmica e continuamente, grava a imagem na película enquanto o obturador permanece aberto e o movimento dura. Assim, o "tempo vem traduzido em espaço" (BRAGAGLIA, 1980, p. 68), ou seja, o tempo se inscreve, através da luz, na película fotográfica.

O movimento da fotodinâmica consiste em visão exotópica ${ }^{9}$ ao fotográfico. Seu embate é uma luta de fronteira, se dá no limiar, não entre a fotografia (chamada até hoje imagem estática) e o cinema e a cronofotografia, mas na fotografia. E, como já dissemos, pelas suas características de intervenção no aparelho, subverte o fotográfico, que fundou e monopolizou o design da comunicação por imagens nos séculos seguidos, de perspectivização da cultura.

Ao examinar o retrato pictórico e o retrato fotográfico, dentro dos estudos da semiótica russa e sob a luz do conceito de semiosfera, Iúri Lótman aponta para a liminaridade:

pode parecer que a diferença entre a fotografia e o retrato está desaparecendo gradualmente. Tal processo, de fato, está ocorrendo, mas, se reduzirmos a esse fato a essência da questão, corremos o risco de perder a fronteira entre essas duas espécies de arte profundamente diferentes (LÓTMAN, 2000, p. 23).

Ora, os estudos de Bakhtin analisam o fenômeno da fronteira, da liminaridade, como o encontro dialógico entre duas totalidades abertas. Observa-se, assim, que, com o Fotodinamismo e o fotográfico, a compreensão de um sistema em relação ao outro se dá justamente por serem um e outro, e apenas esse outro pode, por 
exotopia, compreender esse um, que é o sentido alheio. Conforme Bakhtin: "Um sentido revela-se em sua profundidade ao encontrar e tocar outro sentido, um sentido alheio; estabelece-se entre eles como que um diálogo que supera o caráter fechado e unívoco, inerente ao sentido e à cultura considerada isoladamente" (BAKHTIN, 1997, p. 368).

O Fotodinamismo, como sistema cultural, formulou perguntas nunca antes formuladas ao fotográfico, outro sistema da cultura, e apenas olhando para o fotográfico como um sistema alheio, externo ao Fotodinamismo, é que este pode compreender-se a si mesmo e ao outro sistema com peculiares diferenças, aproximações e autonomia. Esse é um grande mérito dos artistas que formularam a teoria da fotodinâmica.

Perloff (1993, p. 82) afirma que é o "esforço da obra de arte para assimilar o que não é arte e reagir a isso que caracteriza o momento futurista” . A experiência dialógica do Fotodinamismo mobilizouse rumo à diversidade, ao trânsito entre fronteiras. $\mathrm{O}$ mesmo meio, a câmera fotográfica, é utilizado para produzir a fotografia e sua transgressão: a fotodinâmica. O Fotodinamismo realiza-se no trânsito, na desestabilização do gênero fotografia. Também a cronofotografia de Marey e as experiências de Muybridge se localizaram em regiões de fronteira: não eram mais fotografia (embora utilizassem aparelhos com os mesmos princípios das câmeras fotográficas) e ainda não eram cinema (ainda que as imagens fossem posteriormente projetadas segundo o conceito do que viria a se constituir em cinema). E essa desestabilização do gênero, no momento de sua eclosão, demonstrará que a "representação da realidade" perde o sentido e cede espaço para um processo de solidariedade recorrente entre mídias:

10. Embora na língua portuguesa mídia seja um substantivo feminino, preferi manter a citação com o artigo no masculino, conforme a tradução brasileira utilizada em nossos estudos (bibliografia anexa).
Os mídias ${ }^{10}$ - verbal, visual, musical - são cada vez mais usados em conjunção: o futurismo é a época da arte da performance, da chamada poesia do som e do livro de artista. Mas atrás desse impulso para a decomposição, para um rompimento das artérias que produzirão o novo, há uma extraordinária fragilidade e inconstância (PERLOFF, 1993, p. 83). 
Dar visibilidade ao movimento e consequentemente à passagem do tempo implica arrancar do objeto a sua rigidez. O Fotodinamismo é concebido em oposição à pose, à ficcionalidade de um mundo estático. Inseparável da performance, ele só faz sentido no ato, na vida vibrando nos corpos em movimento. Não mais o mundo meramente visível faz sentido como "representação". É o mundo sensorial que se revela capaz de se evidenciar em imagem, dando a ver aquilo que o olho humano não consegue alcançar: mudado o fenômeno concreto a que me referi no início deste ensaio, o modelo artístico criado pela comunicação artística é outro.

O caráter experimental do Fotodinamismo caracterizase pela sua emergência quando a constituição dos sistemas da fotografia, do cinema e da performance se fazia por meio de linguagens extremamente experimentais também. O Fotodinamismo é o resultado visionário, híbrido, do cruzamento de linguagens, tendo como incubadora o conjunto de estudos de Muybridge e, principalmente, de Marey, bem como as também experimentais pinturas cubistas. O Fotodinamismo não poderia se constituir em texto da cultura se não fosse precedido de recursos tecnológicos e de linguagem que ele se proporia primeiro a explorar e depois a refutar.

Por outro lado, no campo dos inumeráveis aperfeiçoamentos técnicos sofridos pelas máquinas perspécticas, desde o seu surgimento até as câmeras fotográficas, o Fotodinamismo vai explorar as potencialidades justamente do aparelho fotográfico como mídia, subvertendo o conceito de "instantânea", de "congelamento de tempo". Vai além, deflagrando nossa compreensão do movimento que ultrapassa aquilo que, até então, conseguíamos perceber: percepção expandida através da intervenção em "aparelhos", como diria Flusser mais de 50 anos depois (FLUSSER, 1998).

Não foi a "reconstrução do movimento" ou a reprodução "anatômica e perfeita da realidade" que interessou aos fotodinamistas, e sim "aquela parte do movimento que produziu a sensação cuja lembrança ainda palpita profundamente em nossa consciência" (BRAGAGLIA, 1980, p. 64, grifo nosso). Indo mais além, não era o gesto visível que viria a se constituir em objeto 
de interesse, e sim o que não é visível - os intervalos entre um ponto do espaço e outro (a trajetória), que o olhos humanos não conseguem captar (ou que a mente não consegue gravar), mas a câmera sim, pois esses intervalos estão inscritos na luz: são os estados interestáticos, intermovimentais, intermomentais de um gesto (BRAGAGLIA, 1980, p. 69).

\section{Possibilidades de o design ser redesenhado}

É a partir dos primeiros anos do século XX que a turbulência do cenário tecnológico torna disponível aos artistas o elemento imprescindível para um novo desenho (design), uma reorganização das informações que "con-formam" o sistema das artes. Da percepção de um ambiente em ávido movimento e de assombro, os artistas esforçam-se para tornar visível a transfiguração do mundo percebido não mais apenas como espaço psicológico humano. É esse limite entre o físico e o mental, essa fronteira tão bem estabelecida a partir do Renascimento que os artistas do avant-guerre passarão a forçar, na esperança de que seja finalmente rompido. Observa-se que os manifestos desse período proclamam univocamente:

\footnotetext{
Tudo se move, tudo corre, tudo se desenrola rápido. Uma figura não é mais estável diante de nós, mas aparece e some incessantemente. Pela persistência da imagem na retina, as coisas em movimento se multiplicam, se deformam, subseguindo-se como vibrações, no espaço que percorrem. Assim um cavalo em corrida não tem quatro patas, tem vinte e os seus movimentos são triangulares [...] (BOCCIONI, 1980a, p. 42).
}

Os artistas do "momento futurista" não pouparam esforços para tornar visível essa atmosfera irradiante, em que finalmente o ponto de vista único da perspectiva artificialis, agora estilhaçada, multiplica-se, deformado, sobreposto, desvairado. Marinetti, o líder, futurista, lança a ideia de reconstrução do mundo, cuja luta maior seria vencer "a hostilidade aparentemente irreduzível que separa nossa carne humana do metal dos motores" (MARINETTI, 1980a, p. 87). 
Cabe aqui ressaltar o paradoxo maior que aponta o grau da ameaça do Fotodinamismo dentro dos ideais renovadores do próprio Futurismo, pois serão os pintores futuristas que expulsarão do interior do futurismo "o metal das câmeras" fotodinamistas, embora se evidencie, através dos manifestos, que tanto pintores como fotodinamistas tinham, através de suas diferentes mídias, um fim comum: derrubar as barreiras entre sujeito e objeto. Essa exclusão nos dá pistas que poderão ser investigadas em posteriores estudos e merece ser examinada, pois vai repercutir em problemas epistemológicos por se resolverem ainda hoje, com o acúmulo progressivo de novas questões relacionadas, desta vez, em nosso momento contemporâneo, à tecnologia digital. Recordemos: traçamos o percurso de nosso raciocínio pelo fotográfico, sistema codificado pela perspectiva. Demonstramos que esse sistema engloba as imagens codificadas por máquinas perspécticas, o que equivale dizer: por cálculos matemáticos que possam ser traduzidos por elas. Nessa análise, pudemos também constatar que a partir do Renascimento a cultura visual foi codificada pela representação da “divina proporção". Pelo ponto de vista dos códigos informacionais do sistema das artes visuais, essa cultura visual, materialmente, constituiu-se em desenhos, pinturas e gravuras. Embora saibamos de experiências anamórficas, que repercutiam, já, desde o Renascimento, consideramos que é a partir do XX, com o surgimento da fotografia propriamente dita, que, ao fixar uma imagem em uma máquina perspéctica, instaura-se, no que diz respeito à criação de imagens, o princípio da automação, e aí emerge a necessidade de delimitar as categorias de imagens em dois grandes grupos, via de regra nomeadas artesanais e técnicas, ou em uma outra variação, em finais do século XX: pré-fotográficas e fotográficas. Às artesanais, ou pré-fotográficas, era conferido status de arte, pois se entendia que eram feitas por mãos humanas (vê-se que essa classificação não releva o fato de que essas imagens ou eram de fato intermediadas por máquinas perspécticas, ou, mesmo que não fossem, se valiam, para sua construção, de modelos matemáticos). E as técnicas, as imagens realizadas com máquinas - no caso estudado, a câmera fotográfica - , eram consideradas "trabalhos menores". 
11. Scharf demonstra como o impressionismo, p. ex., serviu-se dos "borrões", verdadeiros espectros, que eram formados pelo registro fotográfico de corpos em movimento quando a velocidade do obturador ainda era baixa. Por outro lado, era "senso comum" que obter imagens assim "borradas" em fotografia era obter imagens "incorretas", ou seja, com o tempo de exposição muito longo, devido aos limites tecnológicos, o que forçava o aperfeiçoamento da máquina para

obter tempos de exposição mais curtos (SCHARF, 1994, p. 175-190).
Se, de início, a necessidade de categorizar as imagens por esse princípio se originou da evidente perda de terreno comercial por parte dos pintores, cujo mercado foi sendo agressivamente tomado pelos fotógrafos, o avanço das pesquisas técnicas foi ocasionando um diálogo ininterrupto entre linguagens, provocando as mais complexas contaminações. A recodificação dos textos foi provocada por esse contato e por experimentações sucessivas, fosse na pintura, fosse na fotografia, que encontrou nessa oposição por parte do campo artístico um solo fértil para explorar suas possibilidades de linguagem ${ }^{11}$. Dessa maneira, quando o Fotodinamismo declara-se arte, em seu manifesto, alija-se do desígnio de mera subserviência técnica à pintura e mais (ou pior): afirma sua soberania sobre ela. Escancarando dessa maneira uma questão teórica no estudo dos gêneros, até hoje por se resolver.

Uma vez definidos o meio e a subversão dele com as experiências dos fotodinamistas, resta-nos entender que, quando esse meio é transgredido, a nota dominante dentro do sistema discursivo do texto cultural é dissonante. Quando subvertido o meio, a nota, até então dominante, sofre um atravessamento em sua codificação.

Subversão aos meios tem-se tornado um fenômeno cumulativo no cenário das artes, no geral, sem que sequer consigamos dar conta, em termos teóricos, do fenômeno frente às múltiplas possibilidades abertas pela rapidez com que nos chegam novas tecnologias a serem exploradas como meio pelos artistas contemporâneos. Ainda que as reflexões teóricas sobre o fotográfico sejam introdutórias, junto a outros estudos afins, elas sugerem o aprofundamento das linguagens, pelo ponto de vista de sua arquitetônica, conforme nos ensina Bakhtin, mais do que pura e simplesmente sermos levados pelos possíveis encantos das disponibilidades tecnológicas.

Entendo, até o momento, que o emprego da câmera fotográfica pelos fotodinamistas está na confluência das possibilidades de uso da linguagem (do fotográfico), não apenas para alcançar novos resultados plásticos, mas para o agenciamento de novos sentidos inaugurados pela percepção fotodinâmica de um espaço onde a vida está em movimento. Não é o meio que define o gênero. É o que concluo, diante do potencial de relacionar o que o meio já oferece e 
o quanto é possível explorar do que esse meio tem ainda a oferecer, que norteou tanto o pensamento teórico e inquieto de Bragaglia quanto a sua produção artística. Essas ações experimentais com o meio, por iniciativa dos fotodinamistas, desestabilizaram o gênero fotografia, ao mesmo tempo que demonstraram que o fotográfico é um sistema da cultura cuja fronteira é móvel. Tal mobilidade, ou permeabilidade, independe de sua tecnologia ser originada por máquinas perspécticas renascentistas, pelo processamento fotoquímico ou pelo mais recente meio digital. Sem essa compreensão, correremos o risco de incorrer em análises datadas, prematuras e que não se sustentarão sequer no dia seguinte, quando a tecnologia disponibilizada pelo mercado na noite anterior, enquanto dormíamos, já estará ultrapassada. 


\section{Referências}

AUMONT, J. O olho interminável (cinema e pintura). São Paulo: Cosac \& Naify, 2004.

BAKHTIN, M. Estética da criação verbal. São Paulo: Martins Fontes, 1997.

BENJAMIN, W. "Pequena história da fotografia”. In: BENJAMIN, W. Magia e técnica, arte e política: ensaios sobre literatura e história da cultura. (Obras escolhidas vol. 1). São Paulo: Brasiliense, 1986.

BOCCIONI, U. et al. "Manifesto dos pintores futuristas". In: BERNARDINI, A. F. (Org.). O Futurismo italiano: manifestos. São Paulo: Perspectiva, 1980.

BRAGAGLIA, A. G. "Fotodinamismo Futurista". In: BERNARDINI, A. F. (Org.). O Futurismo italiano: manifestos. São Paulo: Perspectiva, 1980.

FLUSSER, V. Ensaio sobre a fotografia: para uma filosofia da técnica. Lisboa: Relógio D’Água, 1998.

. "Sobre a descoberta e a ciência”. Galáxia: Revista

Interdisciplinar de Comunicação, Semiótica, Cultura, São Paulo, n. 3, p. 27- 34, 2002.

GIBSON, J. J. The ecological approach to visual perception. London: Lawrence Erlbaum, 1986.

HOUAISS, A. Dicionário eletrônico Houaiss da língua portuguesa. Versão 2.0.a. São Paulo: Objetiva, 2009. CD-ROM.

JALLAGEAS, N. “A articulação da luz através da palavra”. In: LYRA, B.; GARCIA, W. (Orgs.). Corpo e cultura. São Paulo: ECA/ USP; Xamã, 2001.

. "Corporalidade em trânsito: performances de luz". In: LYRA,

B.; GARCIA, W. (Orgs.). Corpo e imagem. São Paulo: Xamã, 2002.

. "Oscilações do real em corpos transientes: notas sobre $o$

Fotográfico na arte contemporânea (I)". In: GARCIA, W.; NOJOSA, U. (Orgs.). Comunicação \& tecnologia. São Paulo: Nojosa, 2003. 
. "Os gestos de fotografar segundo Vilém Flusser". In: GARCIA, W. (Org.). Corpo E tecnologia. São Paulo: Nojosa; Senac, 2004. CD-ROM.

. Vestígios: a leitura fotografada. Dissertação (Mestrado) -

Escola de Comunicações e Artes, Universidade de São Paulo, São Paulo, 2002.

KEMP, M. The science of art: optical themes in western art from Brunelleschi to Seurat. London: Yale University, 1990.

LISTA, G. Cinema e fotografia futurista. Ginevra-Milano: Skira, 2001

.Futurismo e fotografia. Milan: Edizioni Multhipla, 1979.

LÓTMAN, I. A estrutura do texto artístico. Lisboa: Estampa, 1978.

La semiosfera III: semiótica de las artes y de la cultura.

Madrid: Cátedra, 2000.

MACHADO, I. Escola de semiótica: a experiência de Tártu-Moscou para o estudo da cultura. São Paulo: Ateliê Editorial; Fapesp, 2003.

MANNONI, L. A grande arte da luz e da sombra: arqueologia do cinema. São Paulo: Unesp; Senac, 2003.

MARINETTI, F. T. "Fundação e Manifesto do Futurismo". In: BERNARDINI, A. F. (Org.). O Futurismo italiano: manifestos. São Paulo: Perspectiva, 1980

PERLOFF, M. O momento futurista: avant-garde, avant-guerre e a linguagem da ruptura. São Paulo: Edusp, 1993.

PIGNATARI, D. Informação linguagem comunicação. São Paulo: Cultrix, 1985.

SCHARF, A. Arte y fotografía. Madrid: Alianza Forma, 1994.

TATON, R.; FLOCON, A. A perspectiva. São Paulo: Difusão, 1967.

TODOROV, Tzvetan. Mikhaïl Bakhtine le principe dialogique suivi de Écrits du Cercle de Bakhtine. Paris: Minuit, 1981. 